\title{
The Role of Enterprise Architecture in Building and Sustaining IT - Enabled Organizational Agility
}

\author{
Truth Lumor \\ University of Jyväskylä \\ trlumor@student.jyu.fi
}

\author{
Ari Hirvonen \\ University of Jyväskylä \\ ari.p.hirvonen@jyu.fi
}

\author{
Mirja Pulkkinen \\ University of Jyväskylä \\ mirja.k.pulkkinen@jyu.fi
}

\begin{abstract}
To survive in a dynamic environment, an organization must possess the ability to swiftly sense changes and (re)deploy reconfigurable resources in response to the changes (i.e., organizational agility). The literature suggests information technology (IT) can enable and constrain organizational agility, making ITenabled organizational agility usually fleeting. Drawing on a systematic review of 43 articles and on organizational agility theories, this study identifies two main roles that EA can play in building and sustaining IT-enabled organizational agility. First, EA can endow IT-enabled resources with architectural properties that make them reconfigurable. Second, EA process practices provide the ability to form, continually improve, and redeploy reconfigurable IT-enabled resources in response to emerging changes. The architecture properties and EA process practices, together with their implications are discussed. This study contributes to clarifying the link between EA and IT-enabled organizational agility and to explaining how EA can help build and sustain IT-enabled organizational agility.
\end{abstract}

\section{Introduction}

Organizations are exposed to change drivers that require them to quickly respond. Change drivers include changes in customers' requirements, competition criteria, markets, technological innovations, social factors, and regulations [1]-[3]. For example, currently, the Covid-19 pandemic and its associated regulations are change drivers that have forced nations and organizations to rethink how to operate and be competitive in the new environment created by the pandemic. Indeed, organizations are constantly exposed to changes, and those that fail to respond, e.g., by quickly reconfiguring and redeploying their resources, may lose their competitive positions [4] or may even go bankrupt [5].

Thus, the literature suggests that for organizations to survive in hostile environments, they need to possess a capability called organizational agility [6]. Organizational agility is defined as "the successful exploration of competitive bases (speed, flexibility, innovation proactivity, quality and profitability) through the integration of reconfigurable resources and best practices in a knowledge-rich environment to provide customer-driven products and services in a fast changing market environment" [7, p. 37] emphasis added.

In the information systems (IS) literature, IT is seen as both a change driver and an enabler of organizational agility [6]. We refer to organizational agility that is enabled by IT as IT-enabled organizational agility. For example, IT enables organizational agility when it extends an organization's capability to sense and respond to changes [8]. Also, IT enables organizational agility when it is deployed in the formation of digital options which are IT-enabled capabilities that extend the rich and reachness of an organization's processes and knowledge systems [6].

Nevertheless, in the IS literature, there is an ongoing debate on whether IT contributes to or constrains organizational agility [9], [10]. This debate provides several accounts where IT constrains agility or enables rigidity e.g., [10], [11]. IT may lead to rigidity when it is inflexible, or becomes tightly entangled with other organizational resources, constraining the ability of an organization to untangle, reconfigure and redeploy its resources to meet new strategic imperatives [10]-[12]. Congruent with the above, several researchers observe that the business value of IT is short-lived especially in dynamic environments e.g. [13], [14].

Notwithstanding, the IS literature on organizational agility has focused primarily on the role of IT in extending the sensing and response capabilities of an organization [15], and has paid little attention to the creation and redeployment of reconfigurable resources, which is at the core of [7]'s classical definition of organizational agility. This study contributes to addressing this important gap by drawing on the Enterprise Architecture (EA) literature. 
EA is concerned with coherently linking IT and other organizational resources (e.g., business processes, services, and capabilities) to form and evolve the whole organization [16], [17]. Findings from prior research, e.g., [18]-[20], suggests that EA can support organizational agility. Thus, specifically, this study seeks to answer the question: What role can EA play in building and sustaining IT-enabled organizational agility? It draws on a systematic review of the literature that links EA and organizational agility to answer the research question.

This study contributes to clarifying the link between EA and IT-enabled organizational agility and to improving our understanding of how IT can enable organizational agility in the long-term by highlighting the importance of creating and managing reconfigurable IT-enabled resources.

\section{Organizational Agility}

Organizational agility was initially conceived in the manufacturing literature and later applied to the IS literature [21]. Being a context specific concept, organizational agility is defined based on the context in which it is applied. There are thus several definitions of the concept in the literature [15]. Drawing on a review of several early definitions, assumptions behind, and applications of the concept, Yusuf et al [7] proposed a consolidated definition of organizational agility. They define organizational agility as "the successful exploration of competitive bases (speed, flexibility, innovation proactivity, quality and profitability) through the integration of reconfigurable resources and best practices in a knowledge-rich environment to provide customer-driven products and services in a fast changing market environment" [7, p. 37]. This definition highlights the importance of the competitive base of an organization, reconfigurable resources, best practices, context (knowledge-rich environment), and outcome of organizational agility.

Further, research on organizational agility has highlighted the drivers, capabilities, and providers of organizational agility. Agility drivers are changes, including opportunities and threats, that occur in an organization's environment to which the organization must respond [22]. These changes are organization specific, and their relevance depends on the state of the organization [1]. Agility drivers include, change in customer's requirements, competition criteria, markets, technological innovations, and social factors [1]-[3]. Agility capabilities provide an organization with the ability to respond to changes (i.e., agility drivers) in its environment [1], [23]. These capabilities include responsiveness, competency, flexibility/adaptability, and quickness or speed [1], [2], [23]. Agility providers are the means by which an organization builds its agility capabilities. They include the organization, people, technology and innovation bundled together; for example, by IT [1], [2], [23]. Thus, for an organization to be agile, it needs to amass agility providers from which it derives agility capabilities to address agility drivers.

In the IS literature, an early work by Sambamurthy et al.[6] indicates that an IT can aid organizational agility by bundling organizational resources into digital options that extend the rich and reachness of the organizational resources (e.g., processes and knowledge systems). Indeed, this view supports the complementarity view on business value of IT. The complementarity view suggests that an IT asset can result in value when it is combined with other organizational resources to form an IT-enabled resource with extended or new capabilities needed to meet organizational goals [14], [24]. The IS literature on organizational agility has conceptually (e.g., [8], [25]) and empirically (e.g., [26], [27]) studied how IT can extend the capabilities with which an organization senses (i.e., sensing capability) and responds (i.e., response capability) to change drivers. It has also studied how IT may influence different types of agility including operational agility [12], process agility [28], strategic agility [29], customer agility [27], and IS development agility [30]. The IS literature on organizational agility has also studied the importance of context (e.g., organizational environment) on achieving organizational agility, and the outcomes of organizational agility [15], [28].

Nevertheless, the IS literature on organizational agility has paid little attention to how organizations can sustain IT-enabled organizational agility by creating, maintaining, and redeploying reconfigurable IT-enabled resources. This is an important gap because of the very means by which IT results in value, including organizational agility. Research indicates that an IT can derail organizational agility when the IT is not flexible, or when the IT is tightly combined or coupled with other organizational resources such that it is difficult to reconfigure and redeploy the resources [10]-[12]. Thus, though IT can lead to agility in one instance, it may derail the ability of an organization to attain agility in another. This notion is supported by observations that IT value are short-lived especially in dynamic environments (e.g. [13], [14]), and the contradictory relationship between IT and organizational agility leading to debates on whether IT enables or constrains organizational agility. We argue that this conflicting findings and debates exist largely because the importance of creating and managing reconfigurable ITenabled resources has received little attention in the 
conception of the link between IT and organizational agility.

This study contributes to the IS literature on ITenabled organizational agility by studying how organizations can build and sustain IT-enabled organizational agility through the formation and management of reconfigurable IT-enabled resources.

\section{Enterprise Architecture}

Enterprise architecture (EA) refers to the fundamental structure and structuring of an organization as a bundle of the organization's components and the relationships among the components based on a set of principles that guide the design, representation, and evolution of the organization [17], [31], [32]. Usually, EA is concerned with establishing a coherent link between IT and other organizational resources (e.g., business processes, services, and capabilities) to form and evolve the whole organization [16], [17].

An EA is usually conceived as having two natures; it manifest as a product and a process [33]. The product nature of EA relates to architectural artefacts and architectural deliverables. Architecture artefacts are the conceptual designs and representations of, and the plans needed to implement, an organization's components [31], [34]. Examples include, business capability model, solution design, and roadmaps [31], [34]. Architectural deliverables are the actual manifestation of architectural artefacts, e.g., business capabilities, business services, and information systems components [31], [35]. Thus, EA products consist of EA artifacts and EA deliverables. The process nature of EA relates to the processes by which EA products are created, maintained, redeployed, and retired [33]. The concept, Enterprise Architecture Management (EAM) refers to the process nature of EA. EAM is defined as a set of managerial activities (e.g., governance, and change management) that establishes and continuously improves EA products in a way that supports the formulation and execution of organizational strategy; especially, those relating to change [36], [37, p. 3].

Some scholars have studied the link between EA and organizational agility e.g., [18]-[20]. Venkatesh et al. [38] found that by increasing its EA maturity level, a US hospital was able to achieve operational agility through the integration and standardization of its business processes using IT. Similarly, [39] found that EA maturity influences organizational agility by supporting IT alignment and operational IT effectiveness. Richter and Basten [40] also observed that EA leads to organizational agility through integration, transparency and reuse of services.

We systematically review prior literature to synthesize knowledge on the roles that EA can play in building and sustaining IT-enabled organizational agility.

\section{Research Method}

\subsection{Searching and Selecting Papers}

To collate and synthesis findings from prior research on EA and organizational agility, we performed a systematic literature review [41], [42] using the search string "("Agile" OR "Agility" OR "Adaptive") AND ("Enterprise Architecture" OR "Enterprise Architecture Management")" to search for articles in AIS e-library, ScienceDirect, and Google Scholar. The search was done on 8th August 2019 and was not limited by the year of publication. However, in Google Scholar, the search was done in two bits: up until 2015; and from 2016 to 2019. This allowed us to gather the meta-data of all the 1730 articles. The search returned a total of 3010 articles across the three databases ( See Table 1). We then scanned the articles for appropriateness.

First, the titles and abstracts of the articles were read, eliminating articles that were duplicates, written in other languages aside English, editorials, introduction to conference tracks, and extended abstracts (criteria 1). Second, articles that were not on EA, EAM or related concepts were eliminated (criteria 2). Third, the introduction and conclusions of the remaining articles were read. Articles that discussed EA, EAM, and related concepts broadly without focusing on agility or adaptability were eliminated (criteria 3). Fourth, contents of the remaining papers were quickly skimmed for information on how EA or EAM influence ITenabled organizational agility. Articles that broadly discussed the propensity of EA to contribute to organizational agility without discussing how EA may do so, were eliminated (criteria 4). We were left with 43 articles ( See Table 1) that provided information on the link between EA and organizational agility. Figure 1 presents the distribution of the 43 articles by year of publication.

Table 1. The Results from Literature Search

\begin{tabular}{|l|l|}
\hline Database & No. of Articles \\
\hline AIS e-Library & 249 \\
\hline Science Direct & 1031 \\
\hline Google Scholar & 1730 \\
\hline Total of papers retrieved & $\mathbf{3 0 1 0}$ \\
\hline Elimination Criteria 1 & 298 \\
\hline Elimination Criteria 2 & 1466 \\
\hline Elimination Criteria 3 & 809 \\
\hline Elimination Criteria 4 & 394 \\
\hline Total papers eliminated & 2967 \\
\hline Total no. of papers left & $\mathbf{4 3}$ \\
\hline
\end{tabular}




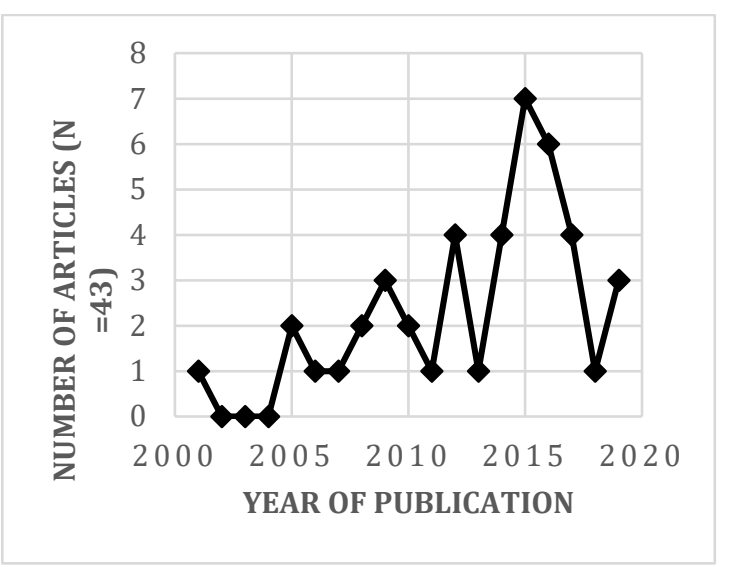

Figure 1 Distribution of Articles by Year of Publication

\subsection{Findings}

We made two notable observations. First, contrary to the findings of other literature reviews that the EA research is mostly conceptual e.g., [43]-[45], we found that most of the papers discussing the relationship between EA and organizational agility are empirical. Given that most of the empirical papers are recent, i.e., from 2014, one could infer that research on EA, especially in this area, is embracing empirics. Second, in line with prior research e.g., [45], [46], we observed that most authors do not employ theories in explaining the relationship between EA and organizational agility.

Table 2. List of Articles Reviewed (Grouped by Type of Article)

\begin{tabular}{|c|c|}
\hline Type of paper & Articles $(\mathrm{N}=43)$ \\
\hline $\begin{array}{l}\text { Conceptual, i.e., } \\
\text { not based on } \\
\text { empirical data } \\
(\mathrm{N}=16)\end{array}$ & $\begin{array}{l}{[47],[48],[49],[50],[51],[52],} \\
{[53],[54],[55],[56],[57],[58],} \\
{[59],[47],[60],[61]}\end{array}$ \\
\hline $\begin{array}{l}\text { Empirical, i.e., } \\
\text { based on } \\
\text { empirical data. } \\
(\mathrm{N}=27)\end{array}$ & $\begin{array}{l}{[62],[39],[63],[64],[65],[66],} \\
{[67],[68],[69],[70],[71],[72],} \\
{[18],[40],[73],[19],[74],[75],} \\
{[38],[76],[77],[20],[78],[79],} \\
{[80],[81],[82]}\end{array}$ \\
\hline
\end{tabular}

\section{Discussions}

The relationship between EA and IT-enabled organizational agility has received considerable attention in the literature e.g., [18]-[20]. In this paper, we draw on a systematic literature review to collate and synthesize knowledge on how EA can support IT- enabled organizational agility, especially in the longterm. We synthesize prior knowledge around the product nature of EA and the process nature of EA. In other words, we synthesize the architectural properties that make EA products reconfigurable, and the EA process practices that support the creation, continuous improvement, and redeployment of EA products (e.g., IT-enabled resources) in response to shifting change drivers. The synthesis is summarized in Table 3 and Table 4, and discussed in sections 5.1 and 5.2.

\subsection{Architectural Properties of EA Products}

The EA literature on the link between EA and organizational agility suggests that for an organization to build and sustain organizational agility, the organization's resources should possess certain architectural properties that make the resources reconfigurable (see Table 3 ). Reconfigurable resources will enable the organization to quickly untangle and reassemble its resources in response to changes. The availability of reconfigurable resources (e.g., reconfigurable IT-enabled resources) is essential for building and sustaining IT-enabled organizational agility [7].

In that regard, the literature suggests that EA products (e.g., IT-enabled resources) should have standardized interfaces and should be loosely coupled with each other enabling the detail of individual EA products to be readily modified without causing arduous architectural burdens or disrupting the functioning of other resources [19], [54]. Further, it should be possible to scale up and down, and to adapt individual EA products to seize new opportunities or to address new changes [53], [64].

Furthermore, EA products should be modular and reusable making it possible for EA teams to readily replace non-performing EA products and quickly reassemble existing EA products in a new way to address emerging strategic imperatives [70], [71]. An EA team is a set of stakeholders, including architects, who are tasked with an aspect of EA. Lastly, EA products should be appropriately represented in a collapsible manner such that each stakeholder can obtain an appropriate view (e.g., high-level or detail view) and a common understanding of EA products [51], [58].

Table 3. Architectural Properties of EA Products

\begin{tabular}{|l|l|}
\hline $\begin{array}{l}\text { Architectural Properties of EA } \\
\text { Products. }\end{array}$ & $\begin{array}{l}\text { Sample } \\
\text { Sources }\end{array}$ \\
\hline $\begin{array}{l}\text { have standardized and loosely coupled } \\
\text { interfaces }\end{array}$ & {$[19],[54]$} \\
\hline be scalable and adaptable (flexible) & {$[53],[64]$} \\
\hline be modular and reusable & {$[70],[71]$} \\
\hline
\end{tabular}


be represented in a collapsible manner

to aid effective communication

\subsection{EA Process Practices}

An organization can build and sustain IT-enable organizational agility by employing EA processes to create, continually improve, and redeploy reconfigurable EA products (e.g., IT-enabled resources). However, the EA literature on organizational agility suggests that for an organization to do so, it should adopt certain EA process practices. We discuss these EA process practices below and summarize them in Table 4.

The organization should define, institutionalize, and use EA principles to ensure that EA products are endowed with architectural properties such as modularity, loose coupling, adaptability and standard interfaces [62], [77]. These architectural properties, as discussed in the previous sub-section, will improve the reconfigurability of EA products, and support ITenabled organizational agility in the long-term.

Further, EA teams should be self-organizing and cross-functional, working with and enabling continuous collaboration among different stakeholders (e.g., IT and business functions of the organization) [69], [72]. Crossfunctional and collaborative approach to EA may serve as an agility provider by improving team building, collaborative relationship, and integration of ideas and processes [2], [3], [7].

Furthermore, EA processes should rely on common terminologies and shared understanding; and EA related knowledge and products should be stored in a repository where they are effectively communicated to all stakeholders [58], [62], [69]. When used as a source of architectural knowledge and products, and made accessible to stakeholders across an organization, an EA repository can enable agility providers and support decision-making capability by providing architectural knowledge based on which timely decisions are made [7]. However, the representation and descriptions of the EA products should just be enough to avoid slowing down EA processes with elaborate documentation processes [58], [69].

Also, the organization should organize its EA initiatives into a series of projects and implement them iteratively with each iteration improving on or incrementally adding new outputs to the outputs of previous iterations [50], [65]. Organizing EA initiatives in this way enables EA teams to timely deliver working EA products (e.g., IT-enabled resources) to stakeholders and to handle changes promptly [50], [52]. It also ensures that EA teams do not treat IT-business alignment and integration as a one-off event but as an on-going process [19], [70]. However, the individual
EA initiatives (whether planned or emergent) should be coordinated synergistically towards achieving and maintaining a coherent EA. Employing an incremental yet coordinated approach to EA enables EA teams to serve as agility providers by providing the capability with which an organization can timely respond to change [1], [2].

Lastly, EA initiatives should incorporate both bottom-up and top-down EA processes that are selfimproving and adaptable to different use contexts [62], [68], [77]. Incorporating bottom-up and top down EA processes allows EA teams to, on the one hand, respond to changes, and take advantage of innovations, from downstream EA processes, and on the other hand, respond to strategic initiatives from upstream EA processes. EA processes that are self-improving and adaptable to different use contexts can be improved based on past experiences, and be used in different contexts; for example, to address planned and emergent changes. Such EA processes serve as agility providers by enabling the capability for flexible and quick response to both downstream and upstream changes, which may be planned or emergent. Further, they allow EA teams to incorporate experiences towards building core competencies over time [2], [3], [7].

Table 4. EA Process Practices

\begin{tabular}{|l|l|}
\hline EA Process Practices & $\begin{array}{l}\text { Sample } \\
\text { Sources }\end{array}$ \\
\hline $\begin{array}{l}\text { Define, institutionalize, and use EA } \\
\text { principles that promote the } \\
\text { reconfigurability of EA products }\end{array}$ & {$[62],[77]$} \\
\hline $\begin{array}{l}\text { Foster continuous participation of, and } \\
\text { collaboration among, different } \\
\text { stakeholders and functions }\end{array}$ & {$[68]$,} \\
\hline $\begin{array}{l}\text { Empower and use self }- \text { organizing EA } \\
\text { teams }\end{array}$ & {$[69],[78]$} \\
\hline $\begin{array}{l}\text { Establish and use common } \\
\text { terminologies to promote shared } \\
\text { understanding }\end{array}$ & {$[72],[52]$} \\
\hline $\begin{array}{l}\text { Use a repository to store and } \\
\text { effectively communicate architecture } \\
\text { knowledge about EA products and } \\
\text { processes }\end{array}$ & {$[51],[62]$} \\
\hline $\begin{array}{l}\text { Enact and coordinate a series of } \\
\text { projects to foster incremental and } \\
\text { phased, yet coherent EA development } \\
\text { and implementation }\end{array}$ & {$[63],[69]$} \\
\hline $\begin{array}{l}\text { Use Iterative EA development and } \\
\text { improvement processes to promote } \\
\text { continuous IT-business alignment and } \\
\text { integration }\end{array}$ & {$[19],[70]$} \\
\hline $\begin{array}{l}\text { Incorporate both bottom-up and top- } \\
\text { down EA processes }\end{array}$ & {$[55],[68]$} \\
\hline
\end{tabular}


EA processes should be self-improving $[52]$, and adaptable to different contexts [72], [77]

\subsection{EA and IT-enabled Organizational Agility}

IT-enabled organizational agility hinges on the fact that IT can be used to extend the sensing and response capabilities of an organization [8] or employed to digitize an organization's processes and knowledge resources in the formation of IT-enabled resources or digital options [6]. However, research shows that combining IT and other resources to extend sensing and response capabilities or to form IT-enabled resources or digital options may result in rigidity, cutting short the enabling effect of IT on organizational agility [10]. In this sub-section, we briefly discuss how the architectural properties of EA products, and the EA process practices can support an organization to build and sustain ITenabled organizational agility.

Based on organizational agility theories, and on the EA literature discussed above, we propose that EA can contribute to building and sustaining IT-enabled organizational agility by providing the ability to form, continually improve, and redeploy reconfigurable ITenabled resources to address shifting strategic imperatives. For an IT-enabled resource to be reconfigurable, it should possess the architectural properties discussed in section 5.1. It should be flexible, modular, reusable, scalable, adaptable, and should have standard interfaces that are loosely coupled with other resources. The architecture properties of an IT-enabled resource may be analyzed at two levels. First, the architectural properties of the IT and organizational resources that are combined to form the IT-enabled resource; and second, the architectural properties of the IT-enabled resource that ensues. Thus, the IT-enabled resource and its components should be endowed with the architectural properties of an EA product.

The EA process practices discussed in section 5.2 act as agility providers that support the design and integration of IT and other resources to form reconfigurable IT-enabled resources. Further, the EA process practices can be employed by EA teams to continually improve, reconfigure, and redeploy ITenabled resources to meet new goals. Thus, equipped with appropriate EA process practices, EA teams can act as response capabilities that quickly and timely (re)combine and integrate reconfigurable IT-enabled resources in pursuit of ever-changing strategic goals. In that regard, besides providing the capability to combine IT and other resources to form IT-enabled resources, EA also provides the capability that makes IT-enabled resources reconfigurable in order to curb rigidity and sustain IT-enabled organizational agility.
Thus, the role of EA in building and sustaining ITenabled organizational agility involves the creation, continuous improvement, and redeployment of reconfigurable IT-enabled resources in response to emerging change drivers, especially in dynamic business environments. In this regard, EA acts mostly as a response capability of an organization. This supports Richter and Basten [40]'s observation that informants in a case organization recounted the effects of EA on response capabilities than they did the effects of EA on sensing capabilities. Nevertheless, in line with MacCormach et al [18], a collaborative approach to EA initiatives that ensures the participation of several stakeholders can support the sensing capabilities of an organization.

Also, EA acts as an agility provider by creating and extending agility capabilities through the formation, improvement, and redeployment of reconfigurable ITenabled resources in response to agility drivers.

\section{Contributions and Implications}

The ability of organizations to swiftly sense change drivers, and swiftly respond by creating and integrating reconfigurable resources is an important organizational capability, called organizational agility, needed to survive in dynamic environments. Organizations without this capability may lose their competitive positions or may even go bankrupt. Research has conceptually and empirically proven the importance of IT in enabling organizational agility (i.e., IT-enabled organizational agility) mostly through the formation of IT-enabled resources that extend the sensing and response capabilities of an organization [8], [27]. However, research has also found that an IT may impede organizational agility when the IT and other resources are inflexible, or are combined in ways that constrain the ability of an organization to decouple, recombine and redeploy the IT and other resources in response to emerging change drivers [10]-[12]. Thus, the effect of IT in enabling organizational agility may be short-lived. This study investigates the role that EA can play in building and sustaining IT-enabled organizational agility. To do so, it draws on a systematic review of the EA literature on organizational agility.

Findings from this study suggest that, the role of EA is twofold. One, EA can endow an IT-enabled resource with architectural properties that make the IT-enabled resource configurable. Second, EA process practices can support the creation, continual improvement, and redeployment of reconfigurable IT-enabled resources (e.g., digital options, and digitized capabilities) in response to changes in the organizational environment.

Findings from this study contribute to the debate on whether IT enables or constrains organizational agility. 
Indeed, IT may both enable and constrain organizational agility. However, our findings suggest that for an organization to build and sustain IT-enabled organizational agility, it is not enough for the organization to possess the capability for combining and integrating IT and other organizational resources to form IT-enabled resources. The organization must also possess a capability that; one, makes the IT-enabled resources reconfigurable; and two, continually improves and redeploys the IT-enabled resources to meet new goals.

In other words, instead of an IT, an organization's capability used to form IT-enabled resources may rather be the main source of rigidity. For instance, two organizations may obtain the same IT asset from an open market. However, one may derive long-term ITenabled organizational agility through the exploration of its capabilities in the formation and redeployment of reconfigurable IT-enabled resources, whereas the other may fail to gain long-term organizational agility because it lacks the capability to form and redeploy reconfigurable IT-enabled resources.

Also, this study contributes architectural properties of EA products and EA process practices that organizations, which seek to build and sustain ITenabled organizational agility, can incorporate into the design of their EA methods and EA maturity models. Research shows that although there are several popular EA frameworks and methods, e.g., TOGAF, organizations tend to design their own local EA frameworks and methods [83], [84]. The findings of this study can be useful to such organization specific EA initiatives. Future research can also explore the findings of this study in the design of EA methods (e.g., agile EAM methods) that promote the agility of the EA function, which is the organizational unit that concerns itself with the conception, implementation, and management of EA [85], and the organization as a whole.

Further, this study clarifies a theoretical link between EA and organizational agility (especially, ITenabled organizational agility). It does so by drawing on EA and organizational agility theories to explain the important roles that EA can play in creating, managing, and redeploying reconfigurable IT-enabled resources.

Practitioners can adopt and leverage the architectural properties and EA process practices discussed in this paper to build and sustain IT-enabled organizational agility.

\section{Limitation and Future Research}

Despite the contributions of this study, it is limited to the findings of the 43 articles that we reviewed. However, drawing on a review of 16 conceptual articles and 27 empirical articles on the link between EA and organizational agility, this study consolidates and improves our understanding of how EA can help build and sustain IT-enabled organizational agility. Since, this is a growing area of research, seeing that most of the articles we reviewed are recent, the findings of this study may serve as the basis upon which future research on EA and organizational agility can build.

Future research can empirically examine the findings of this study. First, future research can examine the findings by studying the extent to which the architectural properties of EA products and EA process practices are included in organizational EA initiatives. Second, future research can examine the findings of this study by drawing on the architectural properties and the EA process practices to design EA methods that improve the agility of the EA function and that of the organization as a whole. Such research efforts can rely on, for example, action design research [86] to design and evaluate agile EA methods and practices in organizations whilst contributing design artefacts that are transferable beyond the case organizations. Third, since organizational context; including strategic orientation [26] and environmental dynamics [28] may influence the quest for and the ability to achieve ITenabled organizational agility; future research should also investigate the environmental context under which the findings of this study are more applicable. For instance, future research can investigate the extent to which the architectural properties and EA process practices are applicable in organizations that embark on digital transformation journeys [87], or that adopt a "bimodal" approach [88] to managing IT and business.

\section{Conclusion}

This study investigates the roles of EA in building and sustaining IT-enabled organizational agility. Drawing on a systematic review of the literature on EA and organizational agility, it collates, and synthesizes the roles that EA can play along the product nature of EA and the process nature of EA. Whereas the product nature of EA elucidates the architectural properties that can make an IT-enabled resource reconfigurable, the process nature of EA prescribes EA process practices that can support the creation, continuous improvement, and redeployment of reconfigurable IT-enabled resources to address emerging change drivers.

This study improves our understanding of the link between EA and IT-enabled organizational agility and contributes towards resolving the on-going debate on whether IT enables organizational agility or rigidity. Areas for future research are discussed and researchers are encouraged to empirically examine the findings of this study in different organizational contexts. 


\section{References}

[1] H. Sharifi and Z. Zhang, "A methodology for achieving agility in manufacturing organisations: An introduction," International journal of production economics, vol. 62, no. 1-2, pp. 7-22, 1999.

[2] Y.-H. Tseng and C.-T. Lin, "Enhancing enterprise agility by deploying agile drivers, capabilities and providers," Information Sciences, vol. 181, no. 17, pp. 3693-3708, 2011.

[3] Z. Zhang and H. Sharifi, "Towards theory building in agile manufacturing strategy-a taxonomical approach," IEEE Transactions on Engineering Management, vol. 54, no. 2, pp. 351-370, 2007.

[4] D. G. Sirmon, M. A. Hitt, J.-L. Arregle, and J. T. Campbell, "The dynamic interplay of capability strengths and weaknesses: investigating the bases of temporary competitive advantage," Strategic Management Journal, vol. 31, no. 13, pp. 1386-1409, 2010.

[5] S. Thornhill and R. Amit, "Learning about failure: Bankruptcy, firm age, and the resource-based view," Organization science, vol. 14, no. 5, pp. 497-509, 2003.

[6] V. Sambamurthy, A. Bharadwaj, and V. Grover, "Shaping agility through digital options: Reconceptualizing the role of information technology in contemporary firms," MIS quarterly, vol. 27, no. 3, pp. 237-263, 2003.

[7] Y. Y. Yusuf, M. Sarhadi, and A. Gunasekaran, "Agile manufacturing: The drivers, concepts and attributes," International Journal of production economics, vol. 62, no. 1-2, pp. 33-43, 1999.

[8] E. Overby, A. Bharadwaj, and V. Sambamurthy, "Enterprise agility and the enabling role of information technology," European Journal of Information Systems, vol. 15, no. 2, pp. 120-131, 2006.

[9] M. Van Oosterhout, E. Waarts, and J. van Hillegersberg, "Change factors requiring agility and implications for IT," European Journal of Information Systems, vol. 15, no. 2, pp. 132-145, 2006.

[10] H. Liang, N. Wang, Y. Xue, and S. Ge, "Unraveling the alignment paradox: how does business-IT alignment shape organizational agility?," Information Systems Research, vol. 28, no. 4, pp. 863-879, 2017.

[11] A. Chakravarty, R. Grewal, and V. Sambamurthy, "Information technology competencies, organizational agility, and firm performance: Enabling and facilitating roles," Information systems research, vol. 24 , no. 4, pp. 976-997, 2013.

[12] S. M. Richardson, W. J. Kettinger, M. S. Banks, and Y. Quintana, "IT and agility in the social enterprise: A case study of st jude children's research hospital's 'Cure4Kids' IT-platform for international outreach," Journal of the Association for Information Systems, vol. 15, no. 1, p. 2, 2014.

[13] R. Kohli and V. Grover, "Business value of IT: An essay on expanding research directions to keep up with the times," Journal of the association for information systems, vol. 9, no. 1, p. 23, 2008.
[14] M. Wade and J. Hulland, "The resource-based view and information systems research: Review, extension, and suggestions for future research," MIS quarterly, vol. 28, no. 1, pp. 107-142, 2004.

[15] P. P. Tallon, M. Queiroz, T. Coltman, and R. Sharma, "Information technology and the search for organizational agility: A systematic review with future research possibilities," The Journal of Strategic Information Systems, vol. 28, no. 2, pp. 218-237, 2019.

[16] D. D. Dang and S. Pekkola, "Systematic Literature Review on Enterprise Architecture in the Public Sector.," Electronic Journal of e-Government, vol. 15, no. 2, 2017.

[17] S. Bischoff, S. Aier, and R. Winter, "Use IT or lose IT? The role of pressure for use and utility of enterprise architecture artifacts," in 2014 IEEE 16th Conference on Business Informatics, 2014, vol. 2, pp. 133-140.

[18] T. Fallmyr and B. Bygstad, "Enterprise architecture practice and organizational agility: An exploratory study," in 2014 47th Hawaii International Conference on System Sciences, 2014, pp. 3788-3797.

[19] A. MacCormack, R. Lagerstrom, D. E. Dreyfus, and C. Y. Baldwin, Building the agile enterprise: IT architecture, modularity and the cost of IT change. Harvard Business School, 2016.

[20] M. Pattij, R. van de Wetering, and R. Kusters, "From Enterprise Architecture Management to Organizational Agility: The Mediating Role of IT Capabilities," 32nd Bled eConference: Humanizing technology for a sustainable society, Bled, Slovenia, June 16-19, 2019, pp. 1-14, 2019.

[21] E. W. Ngai, D. C. Chau, and T. Chan, "Information technology, operational, and management competencies for supply chain agility: Findings from case studies," The Journal of Strategic Information Systems, vol. 20, no. 3, pp. 232-249, 2011.

[22] B. Sherehiy, W. Karwowski, and J. K. Layer, "A review of enterprise agility: Concepts, frameworks, and attributes," International Journal of industrial ergonomics, vol. 37, no. 5, pp. 445-460, 2007.

[23] Z. Zhang and H. Sharifi, "A methodology for achieving agility in manufacturing organisations," International Journal of Operations \& Production Management, vol. 20, no. 4, pp. 496-513, 2000.

[24] S. Nevo and M. R. Wade, "The formation and value of IT-enabled resources: antecedents and consequences of synergistic relationships," Mis Quarterly, pp. 163-183, 2010.

[25] S. Nazir and A. Pinsonneault, "IT and firm agility: an electronic integration perspective," Journal of the Association for Information Systems, vol. 13, no. 3, p. 2, 2012.

[26] M. Queiroz, P. P. Tallon, R. Sharma, and T. Coltman, "The role of IT application orchestration capability in improving agility and performance," The Journal of Strategic Information Systems, vol. 27, no. 1, pp. 4-21, 2018.

[27] S. Zhou, Z. Qiao, Q. Du, G. A. Wang, W. Fan, and X. Yan, "Measuring customer agility from online reviews using big data text analytics," Journal of Management Information Systems, vol. 35, no. 2, pp. 510-539, 2018. 
[28] Y. Chen, Y. Wang, S. Nevo, J. Jin, L. Wang, and W. S. Chow, "IT capability and organizational performance: the roles of business process agility and environmental factors," European Journal of Information Systems, vol. 23, no. 3, pp. 326-342, 2014.

[29] G. Piccoli and B. Ives, "IT-dependent strategic initiatives and sustained competitive advantage: a review and synthesis of the literature," MIS Quarterly, vol. 29, no. 4, pp. 747-776, 2005.

[30] W. A. Cram and S. Newell, "Mindful revolution or mindless trend? Examining agile development as a management fashion," European Journal of Information Systems, vol. 25, no. 2, pp. 154-169, 2016.

[31] V. 9 TOGAF, "9, the open group architecture framework (TOGAF)," The Open Group, vol. 1, 2009.

[32] D. Stelzer, "Enterprise architecture principles: literature review and research directions," in Serviceoriented computing. ICSOC/ServiceWave 2009 workshops, 2009, pp. 12-21.

[33] H. Jonkers, M. M. Lankhorst, H. W. ter Doest, F. Arbab, H. Bosma, and R. J. Wieringa, "Enterprise architecture: Management tool and blueprint for the organisation," Information Systems Frontiers, vol. 8, no. 2, pp. 63-66, 2006.

[34] S. Kurnia, S. Kotusev, P. Taylor, and R. Dilnutt, "Artifacts, Activities, Benefits and Blockers: Exploring Enterprise Architecture Practice in Depth," 2020.

[35] R. Winter and R. Fischer, "Essential layers, artifacts, and dependencies of enterprise architecture," in Enterprise Distributed Object Computing Conference Workshops, 2006. EDOCW'06. 10th IEEE International, 2006, pp. 30-30.

[36] S. Aier, C. Fischer, and R. Winter, "Construction and evaluation of a meta-model for enterprise architecture design principles," 2011.

[37] F. Ahlemann, E. Stettiner, M. Messerschmidt, and C. Legner, Strategic enterprise architecture management: challenges, best practices, and future developments. Springer Science \& Business Media, 2012.

[38] V. Venkatesh, H. Bala, S. Venkatraman, and J. Bates, "Enterprise architecture maturity: The story of the veterans health administration.," MIS Quarterly Executive, vol. 6, no. 2, 2007.

[39] R. V. Bradley, R. M. Pratt, T. A. Byrd, C. N. Outlay, and D. E. Wynn Jr, "Enterprise architecture, IT effectiveness and the mediating role of IT alignment in US hospitals," Information Systems Journal, vol. 22, no. 2, pp. 97-127, 2012.

[40] J. Richter and D. Basten, "Exploring the Influence of Service-oriented Architectures on Organizational Agility-A Case Study," Thirty Fifth International Conference on Information Systems, Auckland 2014, 2014.

[41] F. Rowe, "What literature review is not: diversity, boundaries and recommendations," European Journal of Information Systems, vol. 23, no. 3, pp. 241-255, 2014.

[42] J. Webster and R. T. Watson, "Analyzing the past to prepare for the future: Writing a literature review," MIS quarterly, pp. xiii-xxiii, 2002.
[43] Y. Gong and M. Janssen, "The value of and myths about enterprise architecture," International Journal of Information Management, vol. 46, pp. 1-9, 2019.

[44] M. Schöenherr, "Towards a common terminology in the discipline of enterprise architecture," in International Conference on Service-Oriented Computing, 2008, pp. 400-413.

[45] T. Zheng and L. Zheng, "Examining e-government enterprise architecture research in China: A systematic approach and research agenda," Government Information Quarterly, vol. 30, pp. S59-S67, 2013.

[46] H. Al-Kharusi, S. Miskon, and M. Bahari, "Research Perspective in Enterprise Architecture," 2017.

[47] B. D. Rouhani, H. Shirazi, A. F. Nezhad, and S. Kharazmi, "Presenting a framework for agile enterprise architecture," in 2008 1st International Conference on Information Technology, 2008, pp. 1-4.

[48] H. Shirazi, B. Rouhani, and M. Shirazi, "A Framework for Agile Enterprise Architecture.," International Journal of Intelligent Information Technology Application, vol. 2, no. 4, 2009.

[49] F. Fuchs-Kittowski and D. Faust, "Collaborative Enterprise Architecture Design and Development with a Semantic Collaboration Tool," International Journal of e-Collaboration (IJeC), vol. 5, no. 4, pp. 53-66, 2009.

[50] S. Buckl, F. Matthes, I. Monahov, S. Roth, C. Schulz, and C. M. Schweda, "Towards an agile design of the enterprise architecture management function," in 2011 IEEE 15th International Enterprise Distributed Object Computing Conference Workshops, 2011, pp. 322329.

[51] A. Zimmermann, D. Jugel, R. Schmidt, C. Schweda, and M. Möhring, "Collaborative decision support for adaptive digital enterprise architecture," 2015.

[52] Y. I. Alzoubi, A. Q. Gill, and A. Al-Ani, "Distributed Agile Development Communication: An Agile Architecture Driven Framework.," JSW, vol. 10, no. 6, pp. 681-694, 2015.

[53] D. Karagiannis, "Conceptual modelling methods: the AMME agile engineering approach," in International Conference on Informatics in Economy, 2016, pp. 319.

[54] J. Richter and D. Basten, "In Search of Explanations: Conceptualizing the Relationship between Serviceoriented Architecture and Organizational Agility," Thirty Seventh International Conference on Information Systems (ICIS 2016), Dublin, Ireland, 2016.

[55] X. Yu, Y. Cui, and H. Wang, "Research on an agile enterprise architecture design method," 2016.

[56] J. W. Ross, P. Weill, and D. Robertson, Enterprise architecture as strategy: Creating a foundation for business execution. Harvard business press, 2006.

[57] F. Ni and R. Li, "TOGAF for Agile SOA Modelling," 2017.

[58] J. Ziemann, "Architectural Content Management in Agile Times," 2019.

[59] S. Bente, U. Bombosch, and S. Langade, Collaborative enterprise architecture: enriching EA with lean, agile, and enterprise 2.0 practices. Newnes, 2012. 
[60] F. J. Armour and S. H. Kaisler, "Enterprise architecture: Agile transition and implementation," IT professional, vol. 3, no. 6, pp. 30-37, 2001.

[61] R. Wagter, M. Van Den Berg, J. Luijpers, and M. Van Steenbergen, Dynamic enterprise architecture: how to make it work. John Wiley \& Sons, 2005.

[62] R. Abraham, S. Aier, and R. Winter, "Two speeds of EAM-A dynamic capabilities perspective," in Trends in Enterprise Architecture Research and PracticeDriven Research on Enterprise Transformation, Springer, 2012, pp. 111-128.

[63] B. D. Rouhani, Z. Dehghan, R. Mohamaddoust, and M. Nazari, "A Flexible Enterprise Architecture Management Method (FEAM)," Int. J. of Comp. \& Info. Tech.(IJOCIT), vol. 3, no. 3, pp. 157-172, 2015.

[64] P. Drews, I. Schirmer, B. Horlach, and C. Tekaat, "Bimodal enterprise architecture management: The emergence of a New EAM function for a BizDevOpsbased fast IT," in 2017 IEEE 21st International Enterprise Distributed Object Computing Workshop (EDOCW), 2017, pp. 57-64.

[65] R. E. Giachetti, "A flexible approach to realize an enterprise architecture," Procedia Computer Science, vol. 8, pp. 147-152, 2012.

[66] A. Q. Gill, "Agile enterprise architecture modelling: Evaluating the applicability and integration of six modelling standards," Information and Software Technology, vol. 67, pp. 196-206, 2015.

[67] A. Q. Gill, S. Smith, G. Beydoun, and V. Sugumaran, "Agile enterprise architecture: a case of a cloud technology-enabled government enterprise transformation," presented at the Pacific Asia Conference on Information Systems (PACIS), 2014.

[68] T. Tamm, P. B. Seddon, G. Shanks, P. Reynolds, and K. M. Frampton, "How an Australian Retailer Enabled Business Transformation Through Enterprise Architecture.," MIS Quarterly Executive, vol. 14, no. 4, 2015.

[69] G. Toppenberg, S. Henningsson, and G. Shanks, "How Cisco Systems used enterprise architecture capability to sustain acquisition-based growth," MIS Quarterly Executive, vol. 14, no. 4, pp. 151-168, 2015.

[70] J. Schelp and S. Aier, "SOA and EA-sustainable contributions for increasing corporate agility," in 2009 42nd Hawaii International Conference on System Sciences, 2009, pp. 1-8.

[71] S. Aier and J. Schelp, "How to Preserve Agility in Service Oriented Architectures-An Explorative Analysis," Enterprise Modelling and Information Systems Architectures (EMISAJ), vol. 5, no. 2, pp. 2137, 2010.

[72] M. Hauder, S. Roth, C. Schulz, and F. Matthes, "Agile enterprise architecture management: an analysis on the application of agile principles," 2014.

[73] S. Hanschke, J. Ernsting, and H. Kuchen, "Integrating agile software development and enterprise architecture management," in 2015 48th Hawaii International Conference on System Sciences, 2015, pp. 4099-4108.

[74] R. Yuliana and B. Rahardjo, "Designing an agile enterprise architecture for mining company by using
TOGAF framework," in 2016 4th International Conference on Cyber and IT Service Management, 2016, pp. 1-6.

[75] A. Tiwana and B. Konsynski, "Complementarities between organizational IT architecture and governance structure," Information Systems Research, vol. 21, no. 2, pp. 288-304, 2010.

[76] B. Thummadi, V. D. Khapre, and R. Ocker, "Unpacking Agile Enterprise Architecture Innovation work practices: A Qualitative Case Study of a Railroad Company," 2017.

[77] E. Hosiaisluoma, K. Penttinen, J. Mustonen, and J. Heikkilä, "Lean Enterprise Architecture Method for Value Chain Based Development in Public Sector," in ECDG 2018 18th European Conference on Digital Government, 2018, p. 86.

[78] Ö. Uludağ, M. Kleehaus, N. Reiter, and F. Matthes, "What to Expect from Enterprise Architects in LargeScale Agile Development? A Multiple-Case Study," Twenty-fifth Americas Conference on Information Systems, Cancun, 2019, 2019.

[79] D. Paschek, F. Rennung, A. Trusculescu, and A. Draghici, "Corporate development with agile business process modeling as a key success factor," Procedia Computer Science, vol. 100, pp. 1168-1175, 2016.

[80] M. Pulkkinen and A. Hirvonen, "EA planning, development and management process for agile enterprise development," in Proceedings of the 38th annual Hawaii international conference on system sciences, 2005, pp. 223c-223c.

[81] B. T. Hazen, R. V. Bradley, J. E. Bell, J. In, and T. A. Byrd, "Enterprise architecture: A competence-based approach to achieving agility and firm performance," International Journal of Production Economics, vol. 193, pp. 566-577, 2017.

[82] J. A. Carvalho, "Enterprise architecture as enabler of organizational agility: A municipality case study," $\mathrm{PhD}$ Thesis, 2013.

[83] D. D. Dang and S. Pekkola, "Systematic Literature Review on Enterprise Architecture in the Public Sector.," Electronic Journal of e-Government, vol. 15, no. 2, 2017.

[84] S. Kotusev, "TOGAF-based enterprise architecture practice: an exploratory case study," Communications of the Association for Information Systems, vol. 43, no. 1, p. 20, 2018.

[85] B. Van der Raadt, M. Bonnet, S. Schouten, and H. Van Vliet, "The relation between EA effectiveness and stakeholder satisfaction," Journal of Systems and Software, vol. 83, no. 10, pp. 1954-1969, 2010.

[86] M. K. Sein, O. Henfridsson, S. Purao, M. Rossi, and R. Lindgren, "Action design research," MIS quarterly, pp. 37-56, 2011.

[87] I. Sebastian, J. Ross, C. Beath, M. Mocker, K. Moloney, and N. Fonstad, "How big old companies navigate digital transformation," 2017.

[88] B. Horlach, P. Drews, I. Schirmer, and T. Böhmann, "Increasing the agility of IT delivery: five types of bimodal IT organization," 2017. 